\title{
Relationship between peripheral arterial disease, carotid intima-media thickness and C-reactive protein in elderly diabetic patients
}

\author{
Moatassem Salah Amer ${ }^{1}$, Samia Ahmed Abdul-Rahman ${ }^{1^{*}}$, Wafaa Mostafa Abd-El Gawad ${ }^{1}$, \\ Ibrahim Ahmad Abdel Aal ${ }^{2}$, Ahmad Abdel Khalek Abdel Razek Mohamed ${ }^{3}$, \\ Wessam El-Huseiny Moustafa Abdel Wahab ${ }^{4}$ \\ ${ }_{1}^{1}$ Geriatrics and Gerontology Department, Faculty of Medicine, Ain Shams University, Cairo, Egypt;
*Corresponding Author: sa1382001@,hotmail.com
${ }^{2}$ Clinical Pathology Department, Faculty of Medicine, Mansoura University, Mansoura, Egypt
${ }^{3}$ Radiodiagnosis Department, Faculty of Medicine, Mansoura University, Mansoura, Egypt
${ }^{4}$ Geriatrics and Gerontology Department, Faculty of Medicine, Mansoura University, Mansoura, Egypt
}

Received 23 June 2013; revised 23 July 2013; accepted 30 July 2013

Copyright (C) 2013 Moatassem Salah Amer et al. This is an open access article distributed under the Creative Commons Attribution License, which permits unrestricted use, distribution, and reproduction in any medium, provided the original work is properly cited.

\section{ABSTRACT}

Purpose: To study the association between carotid intima media thickness (CIMT) and high sensitivity CRP (hs-CRP) level as markers for PAD in elderly patients with DM. Subjects: A case-control study on 90 participants aged 60 years and older divided into 60 cases (30 patients with DM alone and 30 patients with DM and comorbidities) and $\mathbf{3 0}$ healthy controls. All were assessed by measuring CIMT, ankle brachial index (AB), and markers for cardiovascular disease such as high-sensitivity CRP (hs-CRP), total cholesterol (TC), triglycerides (TG), high density lipoprotein (HDL), and low density lipoprotein (LDL). Results: hs-CRP levels showed statistically significant difference being highest among patients with DM and comorbidities and lowest among controls $(P<0.001)$. Also, symptoms of PAD were significantly higher among cases than controls. $A B I$ was able to detect PAD in many asymptomatic patients. Color changes were present in only $43.30 \%(n=26)$ of positive PAD cases while delayed wound healing, claudication pain, rest pain, cold extremities, and trophic changes were present in $23.30 \%(n=14)$, $16.71 \%(n=10), 16.71 \%(n=10), 45.00 \%(n=27)$, and $21.7 \%(n=13)$. Using logistic regression analysis revealed that DM, CIMT, and hs-CRP were independent predictors for PAD (OR = 4.194, 7.236, 1.003; $P$ value $=0.044,0.25,0.031$ ) after adjustment of other coronary risk factors such as sex, smoking, hypertension, TC, and TG. Conclusion: Diabetic elderly have higher prevalence of asymptomatic PAD thannon-diabetics using solely ABI. DM, CIMT, and hs-CRP are independent predictors for the occurrence of PAD. Hs-CRP levels are highest among diabetics with comorbidities.

Keywords: Peripheral Arterial Disease; Carotid Intima-Media Thickness; Ankle Brachial Index; C-Reactive Protein; Elderly

\section{INTRODUCTION}

Diabetes mellitus (DM) is a prevalent disease especially among elderly. Egypt was ranked the 10th worldwide for the number of people with DM in 2003 (3.9 million) and this number is expected to reach 7.8 million in 2025 [1].

Persons with DM are at an increased risk for atherosclerosis which is responsible for cardiovascular diseases (CVD) (coronary heart disease, peripheral arterial disease, or cerebrovascular disease) [2]. Atherosclerosis starts by preclinical increase in the thickness of the internal and medial membrane of the arterial wall (intima-media thickness-IMT) [3] together with inflammation of the wall of the artery [4]. Several studies addressed the correlation of C-reactive protein (CRP) as a marker of inflammation to the preclinical increase in IMT [5] and now CRP level has emerged as an interesting novel and clinically useful marker for increased cardiovascular risk [6]. 
Peripheral arterial disease (PAD) is considered an independent risk factor for vascular diseases in other arteries and its prevalence increases with age, resulting in increased rate of cardiovascular events and mortality. On top of that, it adversely affects the functional status of the elderly [7]. In epidemiological reports, PAD prevalence among diabetic patients varies widely among countries, ranging from $6.3 \%$ to $36.1 \%$ but generally; PAD is more frequent among diabetic patients than non-diabetic ones $[8,9]$.

The most objective practical mean of documenting the presence and severity of PAD is the measurement of ankle brachial index (ABI) [10]. It is non-invasive, simple, and at the same time it can be correlated with coronary artery disease [11].

Identifying markers of early PAD — in such a large population at risk (diabetic patients) - can facilitate appropriate and early intervention. For this reason, the aim of this work was to study the association between carotid IMT (CIMT) and high sensitivity CRP (hs-CRP) level as markers for PAD in elderly patients with DM.

\section{PATIENTS AND METHODS}

\subsection{Study Design and Setting}

A case-control study was conducted on 90 participants aged 60 years and older attending outpatient clinic of Specialized Medical Hospital of Mansoura University, Mansoura, Egypt.

Sixty cases were recruited and subdivided into group (1) that included 30 participants suffering from DM with other co morbidities and group (2) including 30 participants suffering from DM alone. Another 30 healthy elderly represented the controls and referred to as group (3).

For purpose of the study, exclusion criteria included any causes of altered CRP level (e.g. current infection, rheumatological disease...etc.).

\subsection{Data Collection}

All participants were subjected to comprehensive geriatric assessment that includes detailed personal and medical history and physical examination. Detailed medical history included common comorbidities in elderly with special focus on PAD, hypertension, cardiovascular diseases as coronary heart disease, and cerebrovascular disease.

\subsection{Laboratory Investigations}

Markers for cardiovascular disease such as high-sensitivity CRP (hs-CRP), total cholesterol (TC), triglycerides (TG), high density lipoprotein (HDL), and low density lipoprotein (LDL) levels were measured.

\subsection{Radiological Assessments}

\subsubsection{Carotid Duplex}

Bilateral B mode-Doppler with color imaging carotid artery duplex was done to evaluate the carotid arteries. Measurement of CIMT was made at a point on the far wall of the common carotid artery, $2 \mathrm{~cm}$ proximal to the bifurcation, from a longitudinal scan plane that showed the intima-media boundaries most clearly. On the screen displaying the frozen magnified image of the far wall of the common carotid artery, two cursors were positioned on the boundaries of the intima-media. The distance between these cursors was recorded to the nearest $0.1 \mathrm{~mm}$ (maximum axial resolution of the scanner) as the IMT. The procedure was repeated for each side of the neck. CIMT is a simple non-invasive way and with high predictive value for cardiovascular complications [12].

\subsubsection{Hand-Held Doppler Ultrasound}

Bilateral measuring of ABI was done. The ABI is the ratio of the highest systolic blood pressure (SBP) in the dorsalis pedis or posterior tibial arteries of each leg to that of the highest SBP in the brachial artery of each arm [13]. During the inflation of a pneumatic cuff, the onset of flow was detected with a hand-held continuous wave Doppler ultrasound device probe placed over the dorsalis pedis and posterior tibial arteries and thus denoting ankle SBP while brachial artery SBP was assessed by the routine method using stethoscope. Decrease in the ABI is consistent with PAD. Mild-to moderate PAD usually produces $\mathrm{ABI}$ in the range of 0.41 to 0.90 . A reading below 0.40 suggests the presence of severe PAD [14].

\subsection{Statistical Analysis}

Data collected was revised, coded, tabulated, and introduced into a personal computer. Statistical analysis was performed using the 16th version of Statistical Package of Social Science (SPSS). Quantitative variables were presented in the form of means and standard deviation. Qualitative variables were presented in form of frequency tables (number and percent). Comparison between quantitative variables was done using t-test to compare two groups and ANOVA to compare more than two groups. Control for overall type I error was performed using the Bonferroni post hoc comparison test. Comparison between qualitative variables was done using Pearson's Chi square test or Fisher's exact. Correlation between two quantitative variables was done using Pearson's correlation co-efficient. Odds Ratio (OR) was also calculated for PAD symptoms between cases and controls. Logistic regression analysis was done to identify the predictor of PAD. P value is considered significant if equal to or less than 0.05 . 


\section{RESULTS}

Ninety patients aged 60 years and more were recruited. Mean age among group (1) was $67.30 \pm 6.82 \mathrm{yr}$, group (2) was $65.83 \pm 5.96 \mathrm{yr}$ and among group (3) was $67.10 \pm$ 9.40 years. Males represented $37.8 \%(\mathrm{n}=34)$ while females represented $62.2 \%(n=56)$ of the study sample (Table 1). As for comorbidities in group (1), 40\% (n $=12)$ had ischemic heart disease and $16.6 \%(n=5)$ had cerebrovascular disease and all of them had hypertension.

Systolic and diastolic blood pressures, weight and hsCRP levels showed statistically significant difference between group (1), (2) and (3) (P value $\leq 0.001,<0.001$,
$0.030,<0.001$ respectively) being all highest among group (1) and lowest among group (3) (Table 1). Post hoc Bonferroni test revealed that the significant differences in systolic and diastolic blood pressures and weight were only between those of group (1) and group (3), while the significant differences in hs-CRP levels were between groups (1) and (3) (P value $<0.001)$, (2) and (3) (P value $<0.001)$, and (1) and (2) (P value $<$ $0.021)$. Hs-CRP levels were highest in group (1) $(1266.67 \pm 392.96 \mathrm{mg} / \mathrm{dl})$ followed by group (2) $(991.6 \pm$ $448.12 \mathrm{mg} / \mathrm{dl})$ then group (3) $(420.43 \pm 303.11 \mathrm{mg} / \mathrm{dl})$ (Table 1).

There is no statistical significant difference regarding other cardiovascular risk factors (male sex, smoking, age,

Table 1. Comparison between the three studied groups as regard qualitative and quantitative variables.

\begin{tabular}{|c|c|c|c|c|}
\hline & DM with co-morbidity group (1) & DM alone group (2) & Controls group (3) & Pvalue \\
\hline \multicolumn{5}{|l|}{ Sex } \\
\hline - Males & $10(33.3 \%)$ & $12(40.0 \%)$ & $12(40.0 \%)$ & 0.828 \\
\hline - Females & $20(66.7 \%)$ & $18(60.0 \%)$ & $18(60.0 \%)$ & \\
\hline Age & $65.83 \pm 5.69$ & $67.30 \pm 6.82$ & $67.10 \pm 9.40$ & 0.713 \\
\hline \multicolumn{5}{|l|}{ Smoking } \\
\hline - Current & $0(0 \%)$ & $3(10.0 \%)$ & $3(10.0 \%)$ & 0.391 \\
\hline - Non-Smoker & $24(80.0 \%)$ & $22(73.3 \%)$ & $24(80.0 \%)$ & \\
\hline - Ex-Smoker & $6(20.0 \%)$ & $5(16.7 \%)$ & $3(10.0 \%)$ & \\
\hline \multicolumn{5}{|l|}{ Marital status } \\
\hline - Single & $1(3.3 \%)$ & $1(3.3 \%)$ & $0(0 \%)$ & 0.911 \\
\hline - Married & $17(56.7 \%)$ & $16(53.3 \%)$ & $16(53.3 \%)$ & \\
\hline - Widow & $12(40.0 \%)$ & $12(40.0 \%)$ & $13(43.3 \%)$ & \\
\hline - Divorced & $0(0 \%)$ & $1(3.3 \%)$ & $1(3.3 \%)$ & \\
\hline Weight & $87.60 \pm 9.88$ & $82.45 \pm 8.80$ & $80.67 \pm 12.07$ & $0.030^{*}$ \\
\hline Height & $165.03 \pm 8.18$ & $166.60 \pm 9.14$ & $163.73 \pm 8.45$ & 0.445 \\
\hline BMI & $32.54 \pm 5.37$ & $29.98 \pm 4.34$ & $30.26 \pm 5.58$ & 0.102 \\
\hline SBP & $131.16 \pm 18.55$ & $115.33 \pm 10.49$ & $114.26 \pm 12.83$ & $0.000^{*}$ \\
\hline DBP & $81.66 \pm 8.23$ & $73.66 \pm 9.27$ & $72.83 \pm 7.6$ & $0.000^{*}$ \\
\hline PAD & $22(73.3 \%)$ & $18(60.00 \%)$ & $10(33.3 \%)$ & 0.549 \\
\hline \multicolumn{5}{|c|}{ Laboratory investigation } \\
\hline - $\mathrm{FBS}$ & $162.50 \pm 56.96$ & $153.27 \pm 63.43$ & $93.93 \pm 10.64$ & $0.000^{*}$ \\
\hline - $\quad 2 \mathrm{hPP}$ & $259.77 \pm 95.01$ & $247.03 \pm 85.11$ & $131.30 \pm 24.74$ & $0.000^{*}$ \\
\hline - Hs.CRP & $1266.67 \pm 392.68$ & $991.6 \pm 448.12$ & $420.43 \pm 303.11$ & $0.000^{*}$ \\
\hline - $\mathrm{TC}$ & $233.97 \pm 45.91$ & $235.70 \pm 43.40$ & $218.27 \pm 46.43$ & 0.265 \\
\hline - $\mathrm{TG}$ & $162.27 \pm 59.12$ & $132.07 \pm 65.81$ & $135.33 \pm 59.21$ & 0.119 \\
\hline - HDL & $52.57 \pm 13.58$ & $47.60 \pm 18.07$ & $50.50 \pm 13.59$ & 0.450 \\
\hline - $\mathrm{LDL}$ & $150.20 \pm 47.37$ & $160.30 \pm 43.74$ & $140.47 \pm 46.23$ & 0.251 \\
\hline CIMT (mm) & $1.082 \pm 0.445$ & $1.0791 \pm 0.223$ & $0.952 \pm 0.232$ & 0.198 \\
\hline ABI & $0.883 \pm 0.145$ & $0.916 \pm 0.159$ & $0.915 \pm 0.105$ & 0.578 \\
\hline
\end{tabular}

BMI: body mass index; SBP: systolic blood pressure; DBP: diastolic blood pressure; PAD: peripheral arterial disease; FBS: fasting blood sugar; $2 \mathrm{hPP}: 2$ hours postprandial; Hs-CRP: high sensitivity C-reactive protein; TC: Total cholesterol; TG: triglycerides; HDL: high density lipoprotein; LDL: low density lipoprotein, CIMT: carotid intima media thickness; ABI: ankle brachial index. "Statistically significant. 
BMI, TC, TG, HDL-C, LDL-C, CIMT, and ABI) between group (1), (2) and (3) (P value $=0.828,0.391,0.713$, $0.102,0.265,0.119,0.450,0.251,0.198,0.578$ respectively) (Table 1).

Although not reaching statistical significance, percentage of PAD was higher in group (1) $(73.3 \%, \mathrm{n}=22)$ and group (2) $(60.00 \%, \mathrm{n}=18)$ than group (3) $(33.3 \%, \mathrm{n}=10)$.

As regard the correlation between diabetes control and complications, group (1) had statistically significant higher use of insulin (100\% vs $73.3 \%)$, symptoms of poor control (96.7\% vs 70\%), cataract (40\% vs $13.3 \%$ ), diabetic neuropathy ( $93.3 \%$ vs 53.3 ), diabetic retinopathy (43.3\% vs $6.7 \%)$, diabetic nephropathy $(20 \%$ vs $0 \%)$ and longer duration in month $(170.40 \pm 80.98$ vs $85.87 \pm$ 72.14) than group (2) (P value $=0.002,0.006,0.020,<$ $0.001,<0.001,0.010,<0.001$ respectively) (Table 2 ).

Generally, symptoms of PAD as color changes, delayed wound healing, claudication pain, resting pain, trophic changes, cold extremities were statistically significantly higher among cases than controls ( $\mathrm{P}$ value $\leq$ $0.001,0.025,0.035,0.034,0.011,0.001)$. Their Odds Ratios were higher for cases than controls. For color changes, delayed wound healing, claudication pain, resting pain, trophic changes, cold extremities, OR were $10.286,5.091,7.250,7.250,9.667$, and 6.111 respectively (Table 3).

Table 2. Comparison between group (1) and group (2) as regard Diabetes Control and Complications.

\begin{tabular}{|c|c|c|c|}
\hline & $\begin{array}{l}\text { DM with } \\
\text { co-morbidity } \\
\text { Group (1) }\end{array}$ & $\begin{array}{l}\text { DM alone } \\
\text { group (2) }\end{array}$ & Pvalue \\
\hline \multicolumn{4}{|l|}{ Type of treatment: } \\
\hline - Insulin & $30(100 \%)$ & $22(73.3 \%)$ & $0.002^{*}$ \\
\hline $\begin{array}{l}\text { - Oral hypoglycemic } \\
\text { drugs }\end{array}$ & 0 & $8(26.7 \%)$ & \\
\hline Symptoms of poor control & $29(96.7 \%)$ & $21(70 \%)$ & $0.006^{*}$ \\
\hline Recurrent infection & $15(50 \%)$ & $9(30 \%)$ & 0.114 \\
\hline Diabetic foot & $6(20 \%)$ & $5(16.7 \%)$ & 0.739 \\
\hline Cataract & $12(40 \%)$ & $4(13.3 \%)$ & $0.020^{*}$ \\
\hline Diabetic neuropathy & $28(93.3 \%)$ & $16(53.3 \%)$ & $0.000^{*}$ \\
\hline Hyperglycemic coma & $10(33.3 \%)$ & $9(30 \%)$ & 0.781 \\
\hline Hypoglycemic attack & $7(23.3 \%)$ & $5(16.7 \%)$ & 0.519 \\
\hline Diabetic retinopathy & $13(43.3 \%)$ & $2(6.7 \%)$ & $0.001^{*}$ \\
\hline Diabetic nephropathy & $6(20.0 \%)$ & $0(0 \%)$ & $0.010^{*}$ \\
\hline $\begin{array}{l}\text { Duration of diabetes in } \\
\text { months (Mean } \pm \text { SD) }\end{array}$ & $170.400 \pm 80.98$ & $85.866 \pm 72.14$ & $0.000^{*}$ \\
\hline
\end{tabular}

${ }^{*}$ Statistically significant.
Table 3. Comparison between cases (groups (1) \& (2)) and controls (group (3)) regarding symptoms of peripheral arterial disease.

\begin{tabular}{ccccc}
\hline & Cases & Controls & OR & P value \\
\hline Color changes & $32(53.3 \%)$ & $3(10 \%)$ & 10.286 & 0.000 \\
Delayed wound healing & $16(26.7 \%)$ & $2(6.7 \%)$ & 5.091 & 0.025 \\
Claudication pain & $12(20 \%)$ & $1(3.3 \%)$ & 7.250 & 0.034 \\
Resting pain & $12(20 \%)$ & $1(3.3 \%)$ & 7.250 & 0.034 \\
Cold extremities & $33(55 \%)$ & $5(16.7 \%)$ & 9.667 & 0.001 \\
Trophic changes & $15(25 \%)$ & $1(3.3 \%)$ & 6.111 & 0.011 \\
\hline
\end{tabular}

OR: odds ratio.

$\mathrm{ABI}$ was able to detect PAD in many asymptomatic patients. Color changes were present in only $50.20 \%(\mathrm{n}=$ 26) of positive PAD cases and delayed wound healing, claudication pain, rest pain, cold extremities, and trophic changes were present in $28.00 \%(\mathrm{n}=14), 20.00 \%(\mathrm{n}=$ $10), 20.00 \%(\mathrm{n}=10), 54.00 \%(\mathrm{n}=27)$, and $26.00 \%(\mathrm{n}=$ 13) (Table 4).

Using logistic regression analysis revealed that DM, CIMT, and hs-CRP were independent predictors for PAD $(\mathrm{OR}=4.194,7.236,1.003 ; \mathrm{P}$ value $=0.044,0.25,0.031)$ after adjustment of other coronary risk factors such as sex, smoking, hypertension, TC, and TG (Table 5).

\section{DISCUSSION}

$\mathrm{DM}$ and its complications represent a major burden to public health. Early diagnosis and management of PVD in the elderly especially in diabetics is very crucial because it is an independent risk factor for vascular diseases in other regions, resulting in increased rate of cardiovascular events and mortality in addition to its impact on physical function $[7,15,16]$.

So a case-control study was performed on 90 elderly to identify the predictors of PAD in elderly diabetic patients. Sixty cases were divided into group (1) that included 30 participants suffering from DM with co-morbidities and group (2) including 30 participants suffering from DM alone. Another 30 healthy elderly represented the controls group (3).

In this study, despite finding no significant difference in the prevalence of PAD between DM cases and controls groups, the symptoms of PAD were statistically significantly more in DM cases than controls.

This study like many other studies found that most elderly men and women with PAD did not suffer symptoms $[7,17]$ as more than half of the PAD cases diagnosed by ABI which were asymptomatic by history and physical examination. In fact a recent database population based study found that age was the strongest risk 
Table 4. Relationship between symptomatic and asymptomatic cases of peripheral arterial disease (PAD).

\begin{tabular}{ccc}
\hline & \multicolumn{2}{c}{ PAD $^{*}$} \\
\cline { 2 - 3 } & Symptomatic & Asymptomatic \\
\hline Color changes & $26(50.20 \%)$ & $24(49.807 \%)$ \\
Delayed wound healing & $14(28.00 \%)$ & $36(72.00 \%)$ \\
Claudication pain & $10(20.00 \%)$ & $40(80.00 \%)$ \\
Rest pain & $10(20.00 \%)$ & $40(80.00 \%)$ \\
Cold extremities & $27(54.00 \%)$ & $23(46.00 \%)$ \\
Trophic changes & $13(26.00 \%)$ & $37(74.00 \%)$ \\
\hline
\end{tabular}

*Diagnosed by Ankle Brachial index and the presence of symptoms of PAD.

Table 5. Logistic regression analysis for predictors of peripheral arterial disease.

\begin{tabular}{cccccc}
\hline & \multirow{2}{*}{ OR } & SE & P value & \multicolumn{2}{c}{$\begin{array}{c}\text { 95\% Confidence } \\
\text { interval }\end{array}$} \\
\cline { 5 - 6 } & & & & Lower & Upper \\
\hline $\begin{array}{c}\text { Gender } \\
\text { (male) }\end{array}$ & 0.433 & 0.766 & 0.274 & 0.096 & 1.941 \\
$\begin{array}{c}\text { Current } \\
\text { smoking }\end{array}$ & 1.417 & 1.120 & 0.756 & 0.135 & 5.545 \\
X-smoker & 0.866 & 0.947 & 0.879 & 0.997 & 1.000 \\
Hs-CRP & 1.003 & 0.001 & $0.031^{*}$ & 0.992 & 1.015 \\
TC & 0.999 & 0.006 & 0.565 & 0.997 & 1.014 \\
TG & 1.005 & 0.004 & 0.188 & 1.290 & 40.607 \\
CIMT & 7.236 & 0.880 & $0.025^{*}$ & 0.141 & 1.573 \\
HTN & 0.471 & 0.616 & 0.221 & 1.042 & 16.887 \\
DM & 4.194 & 0.711 & $0.044^{*}$ & 0.096 & 1.941 \\
Constant & 0.050 & 1.776 & 0.091 & 0.158 & 12.737 \\
\hline
\end{tabular}

OR: odds ratio; PAD: peripheral arterial disease; Hs-CRP: high sensitivity $\mathrm{C}$ reactive protein; TC: total cholesterol; TG: triglycerides; CIMT: carotid intima media thickness; HTN: hypertension; DM: diabetes mellitus. "Statistically significant.

factor for the development of asymptomatic PAD [18]. So, poorer outcomes are expected in asymptomatic elderly patients with concomitant PAD and DM due to delayed diagnosis.

We found that DM, CIMT, and hs-CRP levels were independent predictors for PAD after adjustment for other coronary risk factors as sex, smoking, hypertension, TC, and TG. So, PAD should be suspected in any elderly patient when one or more of these risk factors is present putting in mind that CIMT had the highest odds ratio (7.136) followed by DM (odds ratio $=4.194$ ) and lastly hs-CRP (odds ratio $=1.003$ ).

With age, there were increased IMT and inflammation in the arterial wall due to exposure to advanced glycation end products, which, in turn, stimulate systemic inflammation, oxidative stress, fibrosis, and lipid deposition in the arterial wall especially in DM. An increased CIMT is considered as a sign of early atherosclerosis and as a window for coronary and lower limb arteries $[19,20]$.

DM patients are more likely to present late due to impaired pain perception resulting from associated peripheral neuropathy in those patients. In fact, the presence of concomitant DM in patients with PAD was associated with a 15 -fold increased risk of lower extremity amputation $[21,22]$.

It is also reported that CRP is present in the core of atheromatus plaques in subjects who experienced sudden death [23]. High CRP causes direct reduction in the nitric oxide production and induces monocyte chemotaxis, cytokine release, and tissue factor secretion (110) which eventually predicts adverse vascular events as coronary heart disease and PAD [24-27].

So, we concluded that DM in elderly is associated with higher prevalence of asymptomatic PAD using solely ABI. DM, CIMT, and hs-CRP are independent predictors for the occurrence of PAD. Hs-CRP levels are highest among diabetic group with comorbidities.

\section{REFERENCES}

[1] International Diabetes Federation (2003) Diabetes Atlas. 2nd Edition, International Diabetes Federation, Brussels. http://dx.doi.org/10.2337/diacare.25.5.894

[2] Adler, A.I., Stevens, R.J., Neil, A., Stratton, I.M., Boulton, A.J.M., and Holman, R.R. (2002) UKPDS 59: Hyperglycemia and other potentially modifiable risk factors for peripheral vascular disease in type 2 diabetes. Diabetes Care, 25, 894-899.

http://dx.doi.org/10.2337/diacare.25.5.894

[3] Held, C., Hjemdahl, P., Eriksson, S.V., Björkander, I., Forslund, L. and Rehnqvist, N. (2001) Prognostic implications of intima media thickness and plaques in the carotid and femoral arteries in patients with stable angina pectoris. European Heart Journal, 22, 62-72. http://dx.doi.org/10.1053/euhj.1999.2006

[4] Libby, P. (2002) Inflammation in atherosclerosis. Nature, 420, 868-874. http://dx.doi.org/10.1038/nature01323

[5] Lucas, A.R., Korol, R. and Pepine, C.J. (2006) Inflammation in atheroscelerosis: Some thoughts about acute coronary syndromes. Circulation, 113, 728-732. http://dx.doi.org/10.1161/CIRCULATIONAHA.105.6014 $\underline{92}$

[6] Danesh, J., Wheeler, J.G., Hirschfield, G.M., Eda, S., Eiriksdottir, G., Rumley, A., et al. (2004) C-reactive protein and other circulating markers of inflammation in the prediction of coronary heart disease. The New England Journal of Medicine, 350, 1387-1397. http://dx.doi.org/10.1056/NEJMoa032804

[7] Krishnaswamy, B., Raja, N. and Deepa, S. (2006) A study 
of peripheral vascular disease in elderly and its association with coronary artery disease. Journal of the Indian Academy of Geriatrics, 2, 10-13.

[8] Rhee, S.Y., Guan, H., Liu, Z.M., Cheng, S.W., Waspadji, S., Palmes, P., et al. (2007) Multi-country study on the prevalence and clinical features of peripheral arterial disease in Asian type 2 diabetes patients at high risk of atherosclerosis. Diabetes Research and Clinical Practice, 76, 82-92.

http://dx.doi.org/10.1016/j.diabres.2006.07.029

[9] Hirsch, A.T., Criqui, M.H., Treat-Jacobson, D., Regensteiner, J.G., Creager, M.A., Olin, J.W., et al. (2001) Peripheral arterial disease detection, awareness, and treatment in primary care. JAMA, 286, 1317-1324. http://dx.doi.org/10.1001/jama.286.11.1317

[10] Belch, J.J., Topol, E.J., Agnelli, G., Bertrand, M., Califf, R.M., Clement, D.L., et al. (2003) Critical issues in peripheral arterial disease detection and management: A call to action. Archives International Medicine, 163, 884-892. http://dx.doi.org/10.1001/archinte.163.8.884

[11] Murabito, J.M., Evans, J.C. and Nieto, K. (2002) Prevalence and clinical correlates of peripheral arterial disease in the Framingham Offspring Study. American Heart Journal, 143, 961-965.

http://dx.doi.org/10.1067/mhj.2002.122871

[12] Greenland, P., Abrams, J., Aurigemma, F.P., Bond, M.G., Clark, L.T., Criqui, M.H., et al. (2000) Prevention conference V: Beyond secondary prevention identifying the high risk patient for primary prevention: Noninvasive tests of atherosclerotic burden; writing group III. Circulation, 101, E16-E22.

http://dx.doi.org/10.1161/01.CIR.101.1.e16

[13] Hirsch, A.T., Haskal, Z.J. and Hertzer, N.R. (2006) ACC/ AHA guidelines for the management of patients with peripheral arterial disease (lower extremity, renal, mesenteric, and abdominal aortic): A collaborative report from the American associations for vascular surgery/society for vascular surgery, society for cardiovascular angiography and interventions, society for vascular medicine and biology, society of interventional radiology, and the ACC/ AHA task force on practice guidelines (writing committee to develop guidelines for the management of patients with peripheral arterial disease)-Summary of recommendations. Journal of Vascular and Interventional Radiology, 17, 1383-1397. http://dx.doi.org/10.1097/01.RVI.0000240426.53079.46

[14] Grenon, M.S., Gagnon, J. and Hsiang, Y. (2009) AnkleBrachial index for assessment of peripheral arterial disease. The New England Journal of Medicine, 361, Article ID: e40. http://dx.doi.org/10.1056/NEJMvem0807012

[15] Smith, G.D., Shipley, M.J. and Rose, G. (1990) Intermittent claudication, heart disease risk factors, and mortality. The Whitehall study. Circulation, 82, 1925-1931. http://dx.doi.org/10.1161/01.CIR.82.6.1925

[16] Eagle, K.A., Rihal, C.S., Foster, E.D., Mickel, M.C. and Gersh, B.J. (1994) Long-term survival in patients with coronary artery disease: Importance of peripheral vascular disease. The coronary artery surgery study (CASS) investigators. Journal of the American College of Car- diology, 23, 1091-1095. http://dx.doi.org/10.1016/0735-1097(94)90596-7

[17] McDermott, M.M., Fried, L., Simonsick, E., Ling, S. and Guralnik, J.M. (2000) Asymptomatic peripheral arterial disease is independently associated with impaired lower extremity functioning: The women's health and aging study. Circulation, 101, 1007-1012. http://dx.doi.org/10.1161/01.CIR.101.9.1007

[18] Chen, Y.J., Lin, M.S., Hsu, K.Y., Chen, C.R., Chen, C.M. and Chen, W. (2013) Prevalence of asymptomatic peripheral arterial disease and related risk factors in younger and elderly patients in Taiwan. Angiology, in Press. http://dx.doi.org/10.1177/0003319713480842

[19] Zieman, S.J., Melenovsky, V. and Kass, D.A. (2005) Mechanisms, pathophysiology, and therapy of arterial stiffness. Arteriosclerosis, Thrombosis, and Vascular Biology, 25, 932-943.

http://dx.doi.org/10.1161/01.ATV.0000160548.78317.29

[20] Zieman, S.J. and Kass, D.A. (2004) Advanced glycation endproduct crosslinking in the cardiovascular system: Potential therapeutic target for cardiovascular disease. Drugs, 64, 459-470. http://dx.doi.org/10.2165/00003495-200464050-00001

[21] American Diabetes Association (2003) Peripheral arterial disease in people with diabetes. Diabetes Care, 26, 33333341. http://dx.doi.org/10.2337/diacare.26.12.3333

[22] Bild, D.E., Selby, J.V., Sinnock, P., Browner, W.S., Braveman, P. and Showstack, J.A. (1989) Lower-extremity amputation in people with diabetes. Epidemiology and prevention. Diabetes Care, 12, 24-31. http://dx.doi.org/10.2337/diacare.12.1.24

[23] Burke, A.P., Tracy, R.P., Kolodgie, F., Malcom, G.T., Zieske, A., Kutys, R., et al. (2002) Elevated C-reactive protein values and atherosclerosis in sudden coronary death: Association with different pathologies. Circulation, 105, 2019-2023. http://dx.doi.org/10.1161/01.CIR.0000015507.29953.38

[24] Tracy, R.P., Lemaitre, R.N., Psaty, B.M., Ives, D.G., Evans, R.W., Cushman, M., et al. (1997) Relationship of C-reactive protein to risk of cardiovascular disease in the elderly. Results from the cardiovascular health study and the rural health promotion project. Arteriosclerosis, Thrombosis, and Vascular Biology, 17, 1121-1127. http://dx.doi.org/10.1161/01.ATV.17.6.1121

[25] Roivainen, M., Viik-Kajander, M., Palosuo, T., Toivanen, P., Leinonen, M., Saikku, P., et al. (2000) Infections, inflammation, and the risk of coronary heart disease. Circulation, 101, 252-257. http://dx.doi.org/10.1161/01.CIR.101.3.252

[26] Verma, S., Wang, C.H., Li, S.H., Dumont, A.S., Fedak, P.W.M., Badiwala, M.V., et al. (2002) A self-fulfilling prophecy: C-reactive protein attenuates nitric oxide production and inhibits angiogenesis. Circulation, 106, 913-919. http://dx.doi.org/10.1161/01.CIR.0000029802.88087.5E

[27] Venugopal, S.K., Devaraj, S., Yuhanna, I., Shaul, P. and Jialal, I. (2002) Demonstration that C-reactive protein decreases eNOS expression and bioactivity in human aortic endothelial cells. Circulation, 106, 1439-1441. http://dx.doi.org/10.1161/01.CIR.0000033116.22237.F9 